\title{
Matéria seca, carbono e nitrogênio de raízes de soja e milho em plantio direto e convencional
}

\author{
Ivan Bordin(1), Carmen Silvia Vieira Janeiro Neves(1), Cristiane de Conti Medina(1), \\ Julio Cezar Franchini dos Santos ${ }^{(2)}$, Eleno Torres $^{(2)}$ e Segundo Urquiaga ${ }^{(3)}$
}

\begin{abstract}
(1)Universidade Estadual de Londrina, Centro de Ciências Agrárias, Departamento de Agronomia, Caixa Postal 6001, CEP 86051-990 Londrina, PR. E-mail: ivanbordin@hotmail.com, csvjneve@uel.br, medina@uel.br (2)Embrapa Soja, Caixa Postal 231, CEP 86001-970 Londrina, PR. E-mail: franchin@cnpso.embrapa.br ${ }^{(3)}$ Embrapa Agrobiologia, BR 465, Km 7, CEP 23890-000 Seropédica, RJ. E-mail: urquiaga@cnpab.embrapa.br
\end{abstract}

\begin{abstract}
Resumo - O objetivo deste trabalho foi verificar se o sistema de preparo do solo afeta a distribuição e o acúmulo de matéria seca (MS), carbono (C) e nitrogênio (N) das raízes de soja (Glycine max) e milho (Zea mays), em um Latossolo Vermelho distroférrico muito argiloso. A amostragem das raízes até $1 \mathrm{~m}$ de profundidade foi feita com anéis volumétricos. A distribuição em profundidade e o acúmulo de $\mathrm{MS}, \mathrm{C}$ e $\mathrm{N}$ das raízes não foram influenciados pelo preparo do solo. A densidade de comprimento de raízes na camada de $0-0,10 \mathrm{~m}$ foi de 0,7 a $1,4 \mathrm{~cm} \mathrm{~cm}^{-3} \mathrm{em}$ soja, e de 1,2 a $1,6 \mathrm{~cm} \mathrm{~cm}^{-3} \mathrm{em}$ milho, e decresceu nas demais camadas. O acúmulo de MS das raízes foi de 1,94 a 2,01 $\mathrm{Mg} \mathrm{ha}^{-1} \mathrm{em}$ soja, e de 2,50 a 3,79 $\mathrm{Mg} \mathrm{ha}^{-1} \mathrm{em}$ milho. Houve acúmulo de 0,61 a $0,63 \mathrm{Mg} \mathrm{ha}^{-1}$ de C e de 36,9 a 38,2 $\mathrm{kg} \mathrm{ha}^{-1}$ de $\mathrm{N}$ em soja, e de 0,72 a 1,10 $\mathrm{Mg} \mathrm{ha}^{-1}$ de Ce de 18,78 a 28,48 $\mathrm{kg} \mathrm{ha}^{-1}$ de $\mathrm{N}$ em milho. Independentemente do sistema de preparo do solo, $80 \%$ das raízes situam-se entre $0,43 \mathrm{e}$ $0,54 \mathrm{~m}$ de profundidade em soja, e entre 0,40 e $0,46 \mathrm{~m}$ em milho.
\end{abstract}

Termos para indexação: Glycine max, Zea mays, densidade de comprimento de raízes, manejo do solo, sistemas de preparo.

\section{Dry matter, carbon and nitrogen of soybean and corn roots in conventional tillage and no-tillage systems}

\begin{abstract}
The objective of this work was to examine whether soil tillage systems affect the distribution and accumulation of dry matter (DM), carbon (C) and nitrogen (N) of root systems of soybean (Glycine max) and corn (Zea mays) in a clayey Typic Haplorthox. Volumetric rings were used for root sampling down to $1 \mathrm{~m}$ depth. The distribution in depth and accumulation of DM, C and $\mathrm{N}$ of soybean and corn roots were not affected by soil tillage systems. Root length density was $0.7-1.4 \mathrm{~cm} \mathrm{~cm}^{-3}$ for soybean and $1.2-1.6 \mathrm{~cm} \mathrm{~cm}^{-3}$ for corn in the $0-0.10 \mathrm{~m}$ layer and decreased in the other layers. Root DM input was $1.94-2.01 \mathrm{Mg} \mathrm{ha}^{-1}$ in soybean and $2.50-3.79 \mathrm{Mg} \mathrm{ha}^{-1}$ in corn. For soybean, $\mathrm{C}$ and $\mathrm{N}$ root inputs were $0.61-0.63 \mathrm{Mg} \mathrm{ha}^{-1}$ and $36.9-38.2 \mathrm{~kg} \mathrm{ha}^{-1}$, respectively. For corn, $\mathrm{C}$ and $\mathrm{N}$ root inputs were $0.72-1.10 \mathrm{Mg} \mathrm{ha}^{-1}$ and $18.78-28.48 \mathrm{~kg} \mathrm{ha}^{-1}$, respectively. Independently of the tillage system, $80 \%$ of the roots were concentrated in the upper surface layer 0.43 to $0.54 \mathrm{~m}$ deep for soybean and in the upper surface layer 0.40 to $0.46 \mathrm{~m}$ deep for corn.
\end{abstract}

Index terms: Glycine max, Zea mays, root length density, soil management, soil tillage.

\section{Introdução}

Os solos agrícolas podem atuar como dreno ou fonte de gases de efeito estufa, a depender do sistema de manejo a que forem submetidos (IPCC, 2001). O cultivo intensivo do solo, com aração e gradagens, resulta na diminuição dos estoques de $\mathrm{C}$ orgânico do solo e resulta no aumento do efluxo de $\mathrm{CO}_{2}$ para a atmosfera. No entanto, os sistemas de manejo conservacionistas determinam alterações na ciclagem de $\mathrm{C}$ no sistema solo-atmosfera, com aumento dos estoques de $\mathrm{C}$ orgânico no solo, resultante da diminuição nas taxas de decomposição da matéria orgânica (Bayer et al., 2000). O solo manejado em plantio direto pode apresentar aumento dos estoques de C e de N (Lovato et al., 2004), em comparação ao sistema de preparo convencional, o que indica que a eliminação do revolvimento do solo é uma prática importante na recuperação de solos degradados.

Recentemente, os trabalhos de pesquisa têm dado maior importância ao papel das raízes na preservação ou aumento da matéria orgânica do solo (Gregory, 2006), com avaliações do acúmulo de material orgânico via sistema radicular. A contribuição das raízes ao aporte orgânico das culturas no solo é de 23 a 45\% da matéria seca da parte aérea, conforme a cultura e o manejo utilizados (Prakash et al., 2002). A avaliação 
dessa contribuição é importante, porque o $\mathrm{C}$ radicular apresenta menor taxa de decomposição, quando comparado ao da parte aérea (Balesdent \& Balabane, 1996), além de ficar mais protegido da atividade microbiológica pela capacidade das raízes de penetrar nos microagregados do solo (Calegari, 2006).

A distribuição do sistema radicular de acordo com o sistema de preparo do solo parece seguir um padrão. Tavares Filho el al. (2001) e Vieira (1981) observaram em milho e em soja, respectivamente, que no plantio convencional as raízes se concentravam na camada superficial de um solo solto e que, na semeadura direta, o sistema radicular estava mais bem distribuído no perfil. Ivo \& Mielniczuk (1999) observaram esse mesmo comportamento nos estádios iniciais do milho, mas nos estádios finais não houve diferença entre os sistemas de preparo.

A maioria dos trabalhos de pesquisa sobre a distribuição das raízes, no perfil do solo, é realizada até cerca de 0,50-0,60 $\mathrm{cm}$ de profundidade (Ivo \& Mielniczuk 1999; Tavares Filho et al., 2001; Venzke Filho et al., 2004; Caires et al., 2008). Entretanto, sabese que o sistema radicular pode atingir profundidades bem maiores, como observado por Vieira (1981). $\mathrm{O}$ acúmulo de $\mathrm{C}$ orgânico proveniente de raízes representa a principal forma de adição de $\mathrm{C}$ em subsuperfície, enquanto a incorporação do material orgânico proveniente da parte aérea das culturas ocorre, principalmente, até a profundidade equivalente aos implementos de corte utilizados no manejo do solo, em torno de 0,20-0,30 m (Tormena et al., 2004).

O objetivo deste trabalho foi verificar se o sistema de preparo do solo afeta a distribuição e o acúmulo de matéria seca, carbono e nitrogênio das raízes de soja e milho, em um Latossolo Vermelho distroférrico muito argiloso.

\section{Material e Métodos}

O trabalho foi realizado no Município de Londrina, $\mathrm{PR}$, na área experimental da Embrapa Soja, a $23^{\circ} 23^{\prime} \mathrm{S}$ e $51^{\circ} 11^{\prime} \mathrm{W}$, a $560 \mathrm{~m}$ de altitude. O solo é classificado como Latossolo Vermelho distroférrico (Embrapa, 1999), com textura muito argilosa (787 $\mathrm{g} \mathrm{kg}^{-1}$ de argila, $168 \mathrm{~g} \mathrm{~kg}^{-1}$ de silte e $45 \mathrm{~g} \mathrm{~kg}^{-1}$ de areia) (Cardoso et al., 2006). O clima da região é subtropical úmido (Cfa), com precipitação e temperatura média anuais de $1.615 \mathrm{~mm}$ e $21^{\circ} \mathrm{C}$, respectivamente.
Os sistemas de preparo do solo estavam implantados na área desde 1997, com dois sistemas de rotações de culturas, que alternavam soja e milho no verão, e trigo, tremoço e aveia-preta no inverno (Tabela 1).

No sistema convencional, o solo foi preparado no verão, com arado e grade niveladora e, no inverno, com grade aradora e grade niveladora. $\mathrm{O}$ arado possuía quatro discos com 30" de diâmetro; a grade aradora 20 discos de 26 " de diâmetro, e a grade niveladora, 42 discos de 22" de diâmetro.

No plantio direto, não houve o revolvimento do solo por implementos de corte, além do realizado pelos discos de corte nas linhas de semeadura.

Antes da semeadura, a análise de solo indicou os seguintes valores para o tratamento de semeadura direta $(0,0-0,10 \mathrm{~m}): \mathrm{pH}\left(\mathrm{CaCl}_{2}\right), \quad 4,67 ; \mathrm{MO}$, 23,69 $\mathrm{g} \mathrm{dm}^{-3}$; P, 24,42 $\mathrm{mg} \mathrm{dm}^{-3} ; \mathrm{Al}, 1,5 \mathrm{mmol}_{\mathrm{c}} \mathrm{dm}^{-3}$; $\mathrm{H}+\mathrm{Al}, 40,4 \mathrm{mmol}_{\mathrm{c}} \mathrm{dm}^{-3} ; \mathrm{K}, 4,5 \mathrm{mmol}_{\mathrm{c}} \mathrm{dm}^{-3} ; \mathrm{Ca}$, $37,7 \mathrm{mmol}_{\mathrm{c}} \mathrm{dm}^{-3} ; \mathrm{Mg}, \quad 16,7 \mathrm{mmol}_{\mathrm{c}} \mathrm{dm}^{-3}$; SB, 61,2 mmol $_{\mathrm{c}} \mathrm{dm}^{-3}$; CTC, 99,4 $\mathrm{mmol}_{\mathrm{c}} \mathrm{dm}^{-3} ; \mathrm{V}, 59,04 \%$. Para o preparo convencional, os valores foram os seguintes $(0,0-0,10 \mathrm{~m}): \mathrm{pH}\left(\mathrm{CaCl}_{2}\right), 4,82 ; \mathrm{MO}$, $20,05 \mathrm{~g} \mathrm{dm}^{-3} ; \mathrm{P}, 13,69 \mathrm{mg} \mathrm{dm}^{-3} ; \mathrm{Al}, 0,5 \mathrm{mmol}_{\mathrm{c}} \mathrm{dm}^{-3}$; $\mathrm{H}+\mathrm{Al}, 35,1 \mathrm{mmol}_{\mathrm{c}} \mathrm{dm}^{-3} ; \mathrm{K}^{+}, 4,2 \mathrm{mmol}_{\mathrm{c}} \mathrm{dm}^{-3} ; \mathrm{Ca}^{2+}$, 40,4 $\mathrm{mmol}_{\mathrm{c}} \mathrm{dm}^{-3} ; \mathrm{Mg}^{2+}, 16,5 \mathrm{mmol}_{\mathrm{c}} \mathrm{dm}^{-3} ; \mathrm{SB}$, 61,2 $\mathrm{mmol}_{\mathrm{c}} \mathrm{dm}^{-3}$; CTC, 96,2 $\mathrm{mmol}_{\mathrm{c}} \mathrm{dm}^{-3} ; \mathrm{V}, 63,40 \%$.

Foram avaliadas as culturas de soja (Glycine $\max$ L.) e milho (Zea mays), em 5 de fevereiro de 2006, na fase de florescimento (Liedgens et al., 2000), correspondente aos estádios fenológicos R2

Tabela 1. Rotações de culturas manejadas nos sistemas convencional e direto.

\begin{tabular}{lccc}
\hline Ano & Período & Rotação 1 & Rotação 2 \\
\hline 1997 & Inverno & Aveia-preta & Aveia-preta \\
$1997 / 1998$ & Verão & Milho & Soja \\
1998 & Inverno & Aveia-preta & Tremoço-branco \\
$1998 / 1999$ & Verão & Soja & Milho \\
1999 & Inverno & Trigo & Aveia-preta \\
$1999 / 2000$ & Verão & Soja & Soja \\
2000 & Inverno & Tremoço-branco & Trigo \\
$2000 / 2001$ & Verão & Milho & Soja \\
2001 & Inverno & Aveia-preta & Tremoço-branco \\
$2001 / 2002$ & Verão & Soja & Milho \\
2002 & Inverno & Aveia-preta & Tremoço-branco \\
$2002 / 2003$ & Verão & Soja & Milho \\
2003 & Inverno & Trigo & Trigo \\
$2003 / 2004$ & Verão & Soja & Soja \\
2004 & Inverno & Tremoço-branco & Aveia-preta \\
$2004 / 2005$ & Verão & Milho & Soja \\
2005 & Inverno & Aveia-preta & Trigo \\
$2005 / 2006$ & Verão & Soja & Milho \\
\hline
\end{tabular}


e VT, respectivamente. A soja, variedade BRS 156, foi semeada em 15/11/2005, com espaçamento entre linhas de $0,45 \mathrm{~m}$, com 15 plantas por metro, tratadas com $200 \mathrm{~kg} \mathrm{ha}^{-1}$ do adubo formulado 0-20-20. Para o milho, utilizou-se o híbrido Pionneer 30F33, semeado também em 15/11/2005, com espaçamento entre linhas de $0,9 \mathrm{~m}$ e cinco plantas por metro, tratadas com $200 \mathrm{~kg} \mathrm{ha}^{-1}$ do adubo formulado 0-20-20 no plantio e $80 \mathrm{~kg}$ de $\mathrm{N}$ em cobertura aos 45 dias.

Para a amostragem das raízes, foi utilizado o método do trado modificado, com coleta das amostras por meio de anéis volumétricos (Böhm, 1979). Para isto, foram abertas quatro trincheiras, perpendicularmente à linha de plantio, para cada espécie e sistema de plantio, distanciadas em $0,05 \mathrm{~m}$ das plantas, com largura de $0,9 \mathrm{~m}$ de comprimento e profundidade de $1 \mathrm{~m}$. Nas paredes das trincheiras, foram cravados, com o auxílio de um esticador hidráulico, anéis de ferro de $0,105 \mathrm{~m}$ de diâmetro por $0,10 \mathrm{~m}$ de altura, com volume de $8,65 \times 10^{-4} \mathrm{~m}^{3}$, em sete profundidades $(0,00-0,10$; $0,10-0,20 ; 0,20-0,30 ; 0,30-0,40 ; 0,40-0,60 ; 0,60-0,80$ e $0,80-1,00 \mathrm{~m})$. As amostras foram coletadas em dois locais, em relação às plantas: na linha de plantio, logo abaixo das plantas; e na entrelinha de plantio, a $0,225 \mathrm{~m}$ das plantas de soja e a $0,45 \mathrm{~m}$ das plantas de milho. A cada profundidade, foi obtida uma média do comprimento das raízes contidas nas linhas e nas entrelinhas de plantio (Caires et al., 2008).

Na separação das raízes do solo, cada anel foi lavado com água corrente sobre peneira de malha de $1 \mathrm{~mm}$. As raízes foram submetidas à leitura ótica com scanner, seu comprimento foi analisado com uso do programa SIARCS 3.0 (Jorge et al., 1996), e o comprimento das raízes quantificado.

As raízes foram, posteriormente, levadas à estufa a $65^{\circ} \mathrm{C}$, por 48 horas, para determinação da massa de matéria seca. Foram feitas amostras compostas das raízes de soja e de milho, tendo-se considerado todas as profundidades avaliadas; quatro subamostras para cada espécie foram obtidas para determinação de C e $\mathrm{N}$ (Tedesco et al., 1995). A partir desses dados, foram calculados os valores por hectare, de MS, C e N das raízes, tendo-se como base o volume dos anéis usados na amostragem. Os resultados foram apresentados em relação a cada profundidade de coleta e o total até $1 \mathrm{~m}$ de profundidade. Também foi calculada a profundidade efetiva, que corresponde à profundidade do solo em que se concentram $80 \%$ de todas as raízes observadas a partir da superfície (Klar, 1991).

As culturas de soja e milho foram avaliadas separadamente, e cada qual constituiu um experimento distinto. $\mathrm{O}$ delineamento experimental utilizado foi de blocos ao acaso, com dois tratamentos (preparo convencional e plantio direto) em parcelas de $6 \times 12 \mathrm{~m}$, com quatro repetições. Os parâmetros comprimento, $\mathrm{MS}$, e teor de $\mathrm{C}$ e de $\mathrm{N}$ das raízes foram analisados por profundidade de solo e para o total do perfil até $1 \mathrm{~m}$ de profundidade. Os dados foram submetidos à análise de variância, a 5\% de probabilidade.

\section{Resultados e Discussão}

A concentração de carbono da matéria seca das raízes foi de 3,12 $\mathrm{g} \mathrm{kg}^{-1}$ para a soja, e 2,89 $\mathrm{g} \mathrm{kg}^{-1}$ para o milho, valores que se assemelham aos encontrados na literatura (Prakash et al., 2002; Kundu et al., 2007). No caso do N, a concentração encontrada na MS das raízes foi de $0,19 \mathrm{~g} \mathrm{~kg}^{-1}$ para soja e $0,08 \mathrm{~g} \mathrm{~kg}^{-1}$ para o milho, que também correspondem aos valores citados em outros trabalhos (Ceh-Breznik \& Tajnsek, 2005; Ludidi et al., 2007).

Não foi observada interação entre profundidade e sistemas de preparo do solo. Os valores obtidos para a densidade de comprimento de raízes (Figura 1) ficaram em torno de $1 \mathrm{~cm} \mathrm{~cm}^{-3}$ para soja e $1,5 \mathrm{~cm} \mathrm{~cm}^{-3}$ para milho, na camada mais superficial. Esses resultados foram inferiores aos constatados por Silberbush \& Barber (1985), que observaram 1,19 a $2,44 \mathrm{~cm} \mathrm{~cm}^{-3}$ nas médias de diversas cultivares de soja, e aos de Caires et al. (2008) que observaram 2 a $3 \mathrm{~cm} \mathrm{~cm}^{-3}$ para soja e cerca de $4 \mathrm{~cm} \mathrm{~cm}^{-3}$ para milho; porém, foram superiores aos valores de Venzke Filho et al. (2004), que obtiveram $0,6 \mathrm{~cm} \mathrm{~cm}^{-3}$ para soja e menos de $0,3 \mathrm{~cm} \mathrm{~cm}^{-3}$ para milho, e aos de Cardoso et al. (2006), que constataram 0,28 a $0,38 \mathrm{~cm} \mathrm{~cm}^{-3}$ de raízes de soja, na mesma camada do solo.

Quanto à influência do preparo do solo, não foram constatadas diferenças quanto à densidade de comprimento de raízes, tanto da soja como do milho, entre os sistemas convencional e direto, para todas as profundidades. Ivo \& Mielniczuk (1999), ao avaliar o comprimento radicular do milho, em vários estádios de desenvolvimento (20,30,58, 74 dias), constataram que, dos 20 aos 30 dias, as raízes tiveram um desenvolvimento mais superficial com o plantio 
convencional e mais aprofundado com o plantio direto, mas que também não houve diferença nos últimos estádios avaliados. Também para o milho, Tavares Filho et al. (2001) observaram que, no plantio convencional, as raízes se desenvolviam mais superficialmente, na camada de até aproximadamente $0,15 \mathrm{~m}$ em solo solto, sobre uma camada compactada (pé-de-grade), que limitava a penetração das raízes; enquanto que, no plantio direto por mais de 20 anos, foi observado um sistema radicular mais bem distribuído no perfil do solo, em razão da melhor condição de continuidade estrutural do solo. Essa mesma situação foi verificada em soja por Vieira (1981).
Quanto à densidade de comprimento total de raízes, até um metro de profundidade, e à profundidade efetiva do sistema radicular da soja e do milho, também não foram observadas diferenças entre os sistemas de preparo e nem entre as profundidades (Tabela 2). As profundidades efetivas variaram de 0,43 a $0,54 \mathrm{~m}$, para soja, e 0,40 a $0,46 \mathrm{~m}$ para o milho. Esses valores são semelhantes aos encontrados por Bassoi et al. (1994) que, ao avaliar o perfil do solo até a profundidade de $1 \mathrm{~m}$, encontraram cerca de $70 \%$ do comprimento de raízes de milho a $0,4 \mathrm{~m}$ de profundidade, em um Nitossolo Vermelho.

O acúmulo de matéria seca de raízes no solo não se diferenciou entre os sistemas de plantio, nas duas
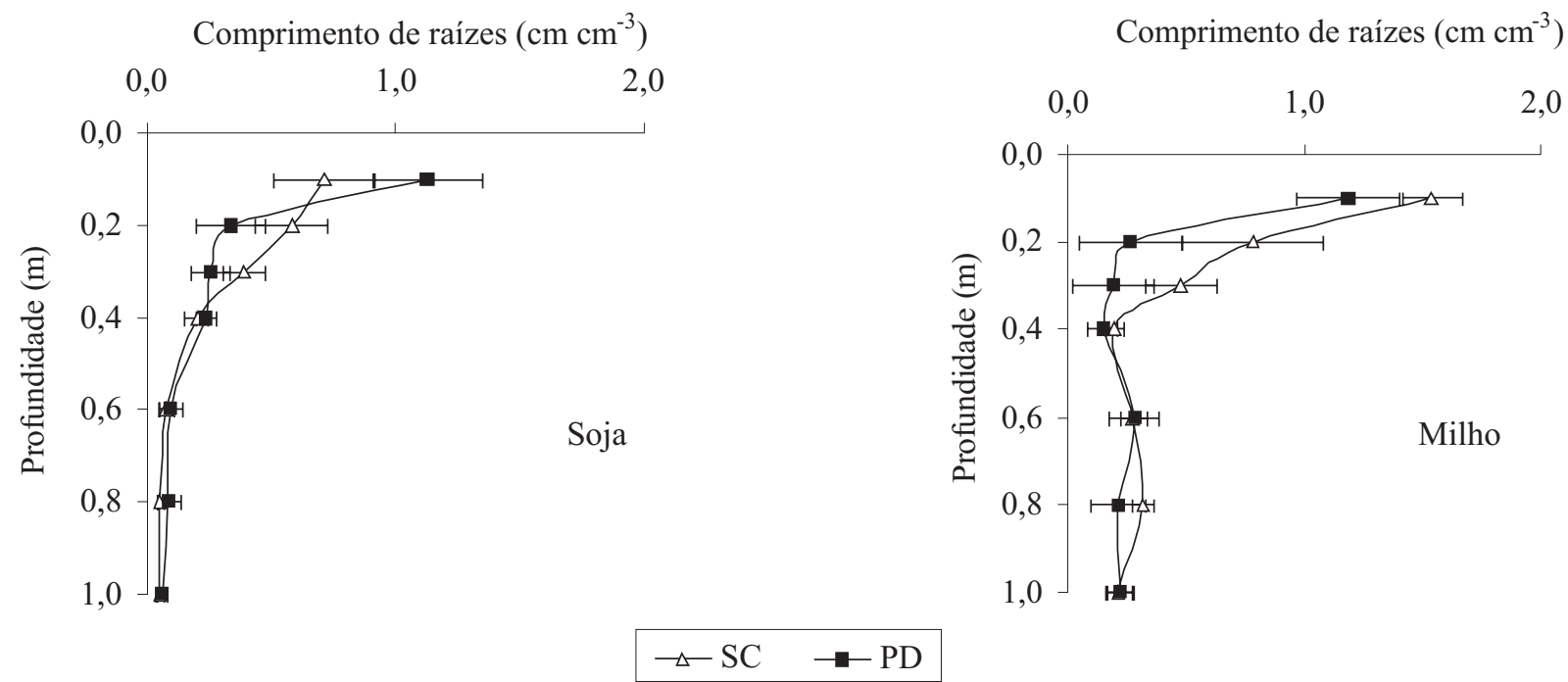

Figura 1. Valores médios e erro-padrão da densidade de comprimento das raízes de soja e de milho, nos sistemas convencional (SC) e plantio direto (PD).

Tabela 2. Densidade de comprimento total de raízes, profundidade efetiva do sistema radicular, e totais de matéria seca, carbono e nitrogênio em raízes de soja e milho, nos sistemas de preparo do solo convencional e semeadura direta, até $1 \mathrm{~m}$ de profundidade ${ }^{(1)}$.

\begin{tabular}{|c|c|c|c|}
\hline \multirow[t]{2}{*}{ Parâmetros } & \multicolumn{2}{|c|}{ Sistema de preparo } & \multirow[t]{2}{*}{$\mathrm{CV}(\%)$} \\
\hline & Convencional & Direto & \\
\hline & \multicolumn{3}{|c|}{ Soja } \\
\hline Comprimento total de raízes $\left(\mathrm{cm} \mathrm{cm}^{-3}\right)$ & $1,95 \mathrm{a}$ & $2,20 \mathrm{a}$ & 25,4 \\
\hline Profundidade efetiva do sistema radicular (m) & $0,43 \mathrm{a}$ & $0,54 \mathrm{a}$ & 19,5 \\
\hline Matéria seca total $\left(\mathrm{Mg} \mathrm{ha}^{-1}\right)$ & $2,01 \mathrm{a}$ & $1,94 \mathrm{a}$ & 16,3 \\
\hline Carbono total $\left(\mathrm{Mg} \mathrm{ha}^{-1}\right)$ & $0,63 \mathrm{a}$ & $0,61 \mathrm{a}$ & 16,2 \\
\hline Nitrogênio total $\left(\mathrm{kg} \mathrm{ha}^{-1}\right)$ & $38,22 \mathrm{a}$ & $36,89 \mathrm{a}$ & 15,9 \\
\hline \multicolumn{4}{|c|}{ Milho } \\
\hline Comprimento total de raízes $\left(\mathrm{cm} \mathrm{cm}^{-3}\right)$ & $3,68 \mathrm{a}$ & $2,99 \mathrm{a}$ & 28,3 \\
\hline Profundidade efetiva do sistema radicular (m) & $0,40 \mathrm{a}$ & $0,46 \mathrm{a}$ & 21,4 \\
\hline Matéria seca total $\left(\mathrm{Mg} \mathrm{ha}^{-1}\right)$ & $3,80 \mathrm{a}$ & $2,51 \mathrm{a}$ & 24,1 \\
\hline Carbono total $\left(\mathrm{Mg} \mathrm{ha}^{-1}\right)$ & $1,10 \mathrm{a}$ & $0,72 \mathrm{a}$ & 23,9 \\
\hline Nitrogênio total $\left(\mathrm{kg} \mathrm{ha}^{-1}\right)$ & $8,48 \mathrm{a}$ & $8,78 \mathrm{a}$ & 23,5 \\
\hline
\end{tabular}

${ }^{(1)}$ Médias seguidas de letras iguais na linha não diferem entre si pelo teste $\mathrm{F}$, a $5 \%$ de probabilidade. 
culturas, em todas as profundidades avaliadas (Figura 2). De Maria et al. (1999) também não encontraram diferenças entre sistema convencional e semeadura direta quanto à produção de matéria seca de raízes de soja. Merten \& Mielniczuk (1991), ao avaliar semeadura direta e sistemas de manejo com revolvimento do solo, também concluíram que não há diferença para a quantidade de matéria seca das raízes de soja, enquanto no milho, há mais matéria seca em sistema convencional do que em plantio direto.
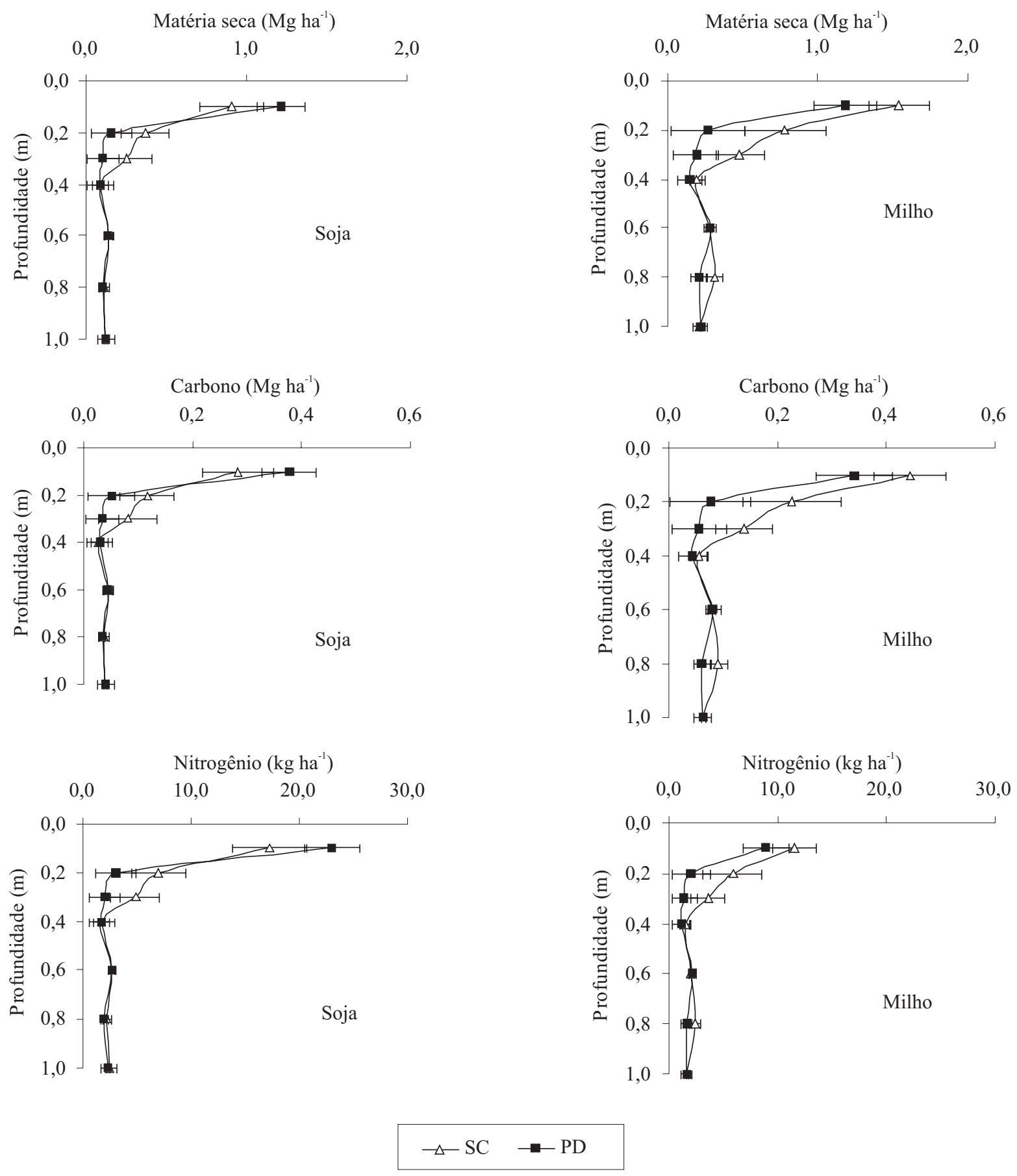

Figura 2. Matéria seca, carbono e nitrogênio das raízes de soja e milho, nos sistemas convencional (SC) e semeadura direta (PD). As barras horizontais representam o erro-padrão das médias. 
Quanto ao acúmulo total de matéria seca das raízes até $1 \mathrm{~m}$ de profundidade, nos dois sistemas de manejo do solo, também não houve diferença entre os tratamentos, para a soja e para o milho (Tabela 2). Os valores foram de 2,01 e 1,94 $\mathrm{Mg} \mathrm{ha}^{-1}$ em soja e de 3,79 e 2,50 $\mathrm{Mg} \mathrm{ha}^{-1}$ em milho, em sistema convencional e semeadura direta, respectivamente.

$\mathrm{O}$ aporte de $\mathrm{C}$ das raízes ao solo também não diferiu entre a semeadura direta e o preparo convencional, tanto na soja quanto no milho, em todas as profundidades avaliadas, e no total, até um metro de profundidade (Figura 2 e Tabela 2). A soja proporcionou aporte de $\mathrm{C}$ de 0,63 e 0,61 $\mathrm{Mg}^{-1}$ e o milho de 1,10 e $0,72 \mathrm{Mg} \mathrm{ha}^{-1}$, nos sistemas convencional e de plantio direto, respectivamente (Tabela 2). Venzke Filho et al. (2004), ao trabalhar em um Latossolo Vermelho escuro, com 22 anos de plantio direto, até $0,5 \mathrm{~m}$ de profundidade, obtiveram valores superiores de C para o milho (1,32 $\left.\mathrm{Mg} \mathrm{ha}^{-1}\right)$ e inferiores para a soja $\left(0,39 \mathrm{Mg} \mathrm{ha}^{-1}\right)$.

Em relação ao aporte de $\mathrm{N}$, também não foram observadas diferenças entre os tratamentos nas profundidades avaliadas e no total, até $1 \mathrm{~m}$ de profundidade, tanto para a soja como para o milho (Figura 2 e Tabela 2). Os valores de $\mathrm{N}$ para a soja foram de 38,22 e $36,89 \mathrm{~kg} \mathrm{ha}^{-1}$ e para o milho de 28,48 e $18,78 \mathrm{~kg} \mathrm{ha}^{-1}$, nos sistemas de plantio convencional e direto, respectivamente. Venzke Filho et al. (2004), ao trabalhar até a profundidade $0,5 \mathrm{~m}$, obtiveram valores inferiores de $\mathrm{N}$ para a soja $\left(20,7 \mathrm{~kg} \mathrm{ha}^{-1}\right)$, e superiores para o milho (58 $\left.\mathrm{kg} \mathrm{ha}^{-1}\right)$. Macedo \& Miranda (2001), ao avaliar um sistema de integração lavoura-pecuária, até $0,2 \mathrm{~m}$ de profundidade, obtiveram $27 \mathrm{~kg} \mathrm{ha}^{-1}$ de $\mathrm{N}$ contido nas raízes de soja, os quais são proporcionalmente bem maiores do que os valores obtidos no presente estudo.

Quanto à distribuição do acúmulo total de $\mathrm{C}$ pelas raízes, em termos percentuais por profundidades (Figura 3), houve maior concentração no plantio direto que no sistema convencional, na profundidade de $0,0-0,1 \mathrm{~m}$, tanto para a soja quanto para o milho, ao contrário do observado em outros trabalhos (Vieira, 1981; Tavares Filho et al., 2001). Leite et al. (2006) também relataram maior incidência de raízes de milho no sistema de plantio direto do que preparo convencional, nos primeiros centímetros de profundidade, em razão de o plantio direto apresentar boas propriedades químicas em superfície, principalmente em relação a $\mathrm{pH}$ e $\mathrm{Ca}^{2+}$, quando há aplicação superficial de calcário sem incorporação ao solo.

Pode-se observar que a maior parte do aporte de C pelas raízes ocorreu a $0,0-0,1 \mathrm{~m}$, com 45 e $62 \%$ para a soja, no sistema de preparo convencional e de plantio direto, respectivamente; e 40 e $47 \%$ para o milho, no sistema convencional e direto, respectivamente. $\mathrm{O}$ aporte de $\mathrm{C}$ pelas raízes, nos dois sistemas e nas duas espécies, diminuiu até as profundidades de $0,1-0,2$ e $0,2-0,3 \mathrm{~m}$, e estabilizou-se nas camadas mais profundas (Figura 3 ).

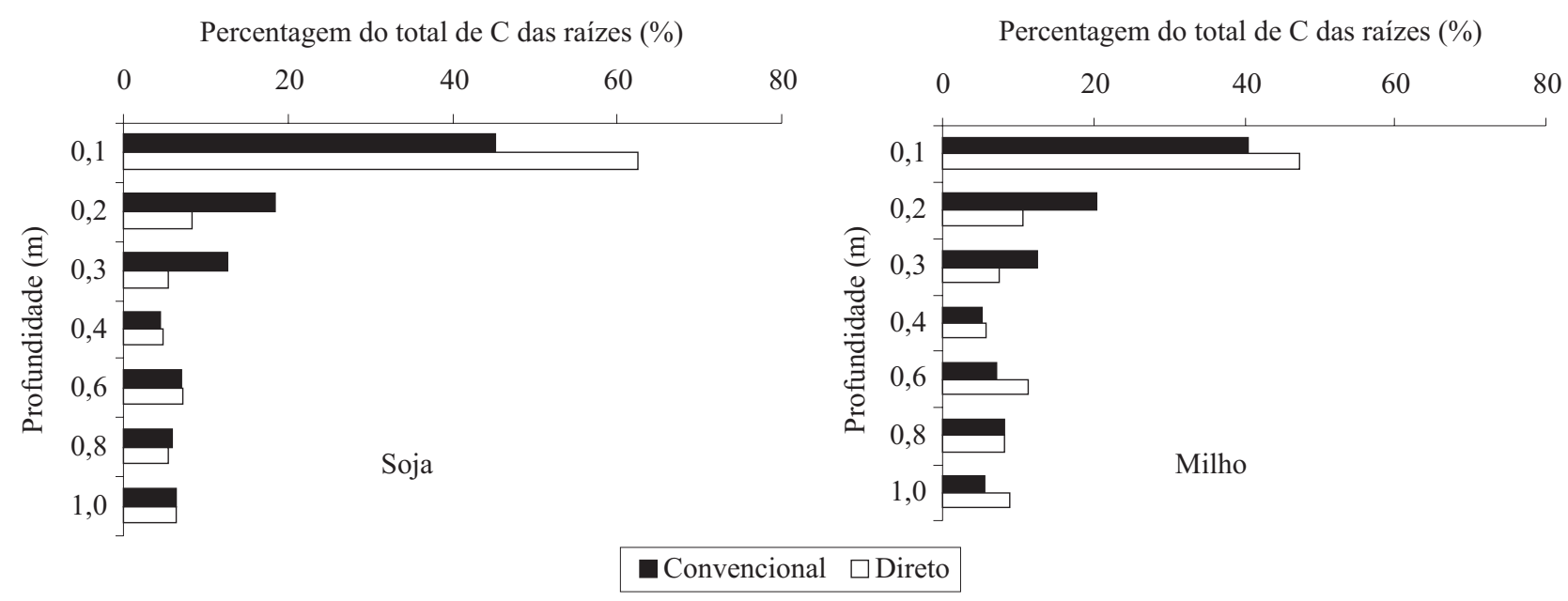

Figura 3. Distribuição de carbono das raízes de soja e milho, em diferentes profundidades do solo, nos sistemas convencional e de semeadura direta. 


\section{Conclusões}

1. Adistribuição das raízes de soja e milho no perfil do solo e o acúmulo de matéria seca, carbono e nitrogênio das raízes dessas culturas não são influenciados pelos sistemas de preparo do solo.

2. Independentemente do sistema de preparo do solo, a profundidade efetiva do sistema radicular da soja situa-se entre 0,43 e $0,54 \mathrm{~m}$, e a do milho, entre 0,40 e $0,46 \mathrm{~m}$.

\section{Agradecimentos}

Ao Conselho Nacional de Desenvolvimento Científico e Tecnológico e ao Projeto de Apoio ao Desenvolvimento de Tecnologias Agropecuárias para o Brasil, por concessão de bolsas e apoio financeiro.

\section{Referências}

BALESDENT, J.; BALABANE, M. Major contribution of roots to soil carbon storage inferred from maize cultivated soils. Soil Biology and Biochemistry, v.28, p.1261-1263, 1996.

BASSOI, L.H.; FANTE JÚNIOR, L.; JORGE, L.A.C.; CRESTANA, S.; REICHARDT, K. Distribuição do sistema radicular do milho em Terra Roxa Estruturada Latossólica: II. Comparação entre cultura irrigada e fertirrigada. Scientia Agricola, v.51, p.541-548, 1994.

BAYER, C.; MIELNICZUK, J.; AMADO, T.J.C.; MARTIM NETO, L.; FERNANDES, S.V. Organic matter storage in a sandy clay loam Acrisol affected by tillage and cropping systems in Southern Brazil. Soil \& Tillage Research, v.53, p.101-109, 2000.

BÖHM, W. Methods of studying root systems. Berlim: Springer Verlag, 1979. 188p.

CAIRES, E.F.; GARBUIO, F.J.; CHURKA, S.; BARTH, G.; CORRÊA, J.C.L. Effects of soil acidity amelioration by surface liming on no-till corn, soybean, and wheat root growth and yield. European Journal of Agronomy, v.28, p.57-64, 2008.

CALEGARI, A. Seqüestro de carbono, atributos físicos e químicos em diferentes sistemas de manejo em um Latossolo argiloso do Sul do Brasil. 2006. 191p. Tese (Doutorado) Universidade Estadual de Londrina, Londrina.

CARDOSO, E.G.; ZOTARELLI, L.; PICCININ, J.L.; TORRES, E.; SARAIVA, O.F.; GUIMARÃES, M.F. Sistema radicular da soja em função da compactação do solo no sistema de plantio direto. Pesquisa Agropecuária Brasileira, v.41, p.493-501, 2006.

CEH-BREZNIK, B.; TAJNSEK,A. Distribution of nitrogen in wheat plant in its late growth stages with regard to organic fertilization and mineral nitrogen rate. Plant, Soil and Environment, v.51, p.553-561, 2005.

DE MARIA, I.C.; CASTRO, O.M.; SOUZA DIAZ, H. Atributos físicos do solo e crescimento radicular de soja em Latossolo Roxo sob diferentes métodos de preparo do solo. Revista Brasileira de Ciência do Solo, v.25, p.703-709, 1999.
EMBRAPA. Empresa Brasileira de Pesquisa Agropecuária. Sistema Brasileiro de Classificação de Solos. Rio de Janeiro: Embrapa Solos, 1999. 412p.

GREGORY, P.J. Roots, rhizosphere and soil: the route to a better understanding of soil science? European Journal of Soil Science, v.57, p.2-12, 2006.

IPCC. Intergovernmental Panel on Climate Change. Climate change 2001: the scientific basis. Cambridge: Cambridge University Press, 2001. 881p.

IVO, W.M.P.M.; MIELNICZUK, J. Influência da estrutura do solo na distribuição e na morfologia do sistema radicular do milho sob três métodos de preparo. Revista Brasileira de Ciência do Solo, v.23, p.135-143, 1999.

JORGE, L.A.C.; RALISCH, R.; ABI SAAB, O.J.G.; MEDINA, C.C.; GUIMARÃES, M.F.; NEVES, C.S.V.J.; CRESTANA, S.; CINTRA, F.L.D.; BASSOI, L.H.; FERNANDES, S.B.V. Aquisição de imagens de raízes. In: JORGE, L.A.C. (Ed.). Recomendações práticas para aquisição de imagens digitais analisadas através do SIARCS. São Carlos: Embrapa-CNPDIA, 1996. p.2-28. (Circular Técnica, 1).

KLAR, A.E. Irrigação: freqüência e quantidade de aplicação. São Paulo: Nobel, 1991. 156p.

KUNDU, S.; BHATTACHARYYA, R.; PRAKASH, V.; GHOSH, B.N.; GUPTA, H.S. Carbon sequestration and relationship between carbon addition and storage under rainfed soybean-wheat rotation in a sandy loam soil of the Indian Himalayas. Soil \& Tillage Research, v.92, p.87-95, 2007.

LEITE, G.H.M.N.; ELTZ, F.L.F.; AMADO, T.J.C.; COGO, N.P. Atributos químicos e perfil de enraizamento de milho influenciados pela calagem em semeadura direta. Revista Brasileira de Ciência do Solo, v.30, p.685-693, 2006.

LIEDGENS, M.; SOLDATI, A.; STAMP, P.; RICHNER, W. Root development of maize (Zea mays L.) as observed with minirhizotrons in lysimeters. Crop Science, v.40, p1665-1672, 2000.

LOVATO, T.; MIELNICZUK, J.; BAYER, C.; VEZZANI, F. Adição de carbono e nitrogênio e sua relação com os estoques no solo e com o rendimento do milho em sistemas de manejo. Revista Brasileira de Ciência do Solo, v.28, p.175-187, 2004.

LUDIDI, N.N.; PELLNY, T.K.; KIDDLE, G.; DUTILLEUL, C.; GROTEN, K.; VAN HEERDEN, P.D.R.; DUTT, S.; POWERS, S.J.; RÖMER, P.; FOYER, C.H. Genetic variation in pea (Pisum sativum L.) demonstrates the importance of root but not shoot $\mathrm{C} / \mathrm{N}$ ratios in the control of plant morphology and reveals a unique relationship between shoot length and nodulation intensity. Plant, Cell and Environment, v.30, p.1256-1268, 2007.

MACEDO, M.C.M.; MIRANDA, C.H.B. Fixação de nitrogênio pela soja em sistemas de cultivo contínuo e rotacionado com pecuária nos cerrados. Campo Grande: Embrapa Gado de Corte, 2001. 29p. (Boletim de Pesquisa e Desenvolvimento, 14).

MERTEN, G.H.; MIELNICZUK, J. Distribuição de sistema radicular e dos nutrientes em Latossolo Roxo sob dois sistemas de preparo do solo. Revista Brasileira de Ciência do Solo, v.15, p.369-374, 1991.

PRAKASH, V.; KUNDU, S.; GHOSH, B.N.; SINGH R.D.; GUPTA, H.S. Annual carbon input to soil through rainfed soybean 
(Glycine max)-wheat (Triticum aestivum) cropping sequence in mid-hills of Northwest Himalaya. Indian Journal of Agricultural Sciences, v.72, p.14-17, 2002.

SILBERBUSH, M.; BARBER, S.A. Root growth, nutrient uptake and yield of soybean cultivars grown in the field. Communications in Soil Science and Plant Analysis, v.16, p.119-127, 1985.

TAVARES FILHO, J.; BARBOSA, G.M.C.; GUIMARÃES, M.F.; FONSECA, I.C.B. Resistência à penetração e desenvolvimento do sistema radicular do milho (Zea mays) sob diferentes sistemas de manejo em Latossolo Roxo. Revista Brasileira de Ciência do Solo, v.25, p.725-730, 2001.

TEDESCO, M.J.; GIANELLO, C.; BISSANI, C.A.; BOHNEN, H.; VOLKWEISS, S.J. Análise de solo, plantas e outros materiais. 2.ed. Porto Alegre: UFRGS, 1995. 174p. (Boletim Técnico de Solos, 5).

TORMENA, C.A.; FRIEDRICH, R.; PINTRO, J.C.A.; COSTA, C.S.; FIDALSKI, J. Propriedades físicas e taxa de estratificação de carbono orgânico num Latossolo Vermelho após dez anos sob dois sistemas de manejo. Revista Brasileira de Ciência do Solo, v.28, p.1023-1031, 2004.

VENZKE FILHO, S.P.; FEIGL, B.J.; PICCOLO, M.C.; FANTE JÚNIOR, L.; SIQUEIRA NETO, M.; CERRI, C.C. Root systems and soil microbial biomass under no-tillage system. Scientia Agricola, v.61, p.529-537, 2004.

VIEIRA, M.J. Propriedades físicas do solo. In: IAPAR. Instituto Agronômico do Paraná. Plantio direto no Estado do Paraná. Londrina, 1981. p.19-32. (Circular técnica, 23).

Recebido em 25 de julho de 2008 e aprovado em 27 de novembro de 2008 